\title{
A LEI DA NOVA POLÍTICA NACIONAL DOS RESÍDUOS SÓLIDOS FACE AO SISTEMA DE COLETA SELETIVA DO MUNICÍPIO DE SANTA MARIA
}

\author{
Tatiéle Cardoso Monteiro ${ }^{1}$ \\ Maria Beatriz Oliveira da Silva ${ }^{2}$ \\ Jaqueline Difante ${ }^{3}$
}

\begin{abstract}
RESUMO
Este artigo tem como objetivo fazer uma breve análise acerca de alguns dos instrumentos de inovação trazidos pela Lei $12.305 / 10$, no que se refere ao tratamento de resíduos sólidos urbanos face ao incremento do consumo da sociedade, destacando a relevância dada à coleta seletiva e às associações de catadores, como forma de viabilizar um meio ambiente sustentável. Ainda, deter-se-á a uma análise da realidade local, tentando demonstrar de que forma tem sido implementada esta política no Município de Santa Maria, através de dados e informações obtidas diretamente com a Associação de Selecionadores de Materiais Recicláveis de Santa Maria, responsável pela realização de tal serviço. Por fim, serão analisadas algumas das dificuldades enfrentadas pelos catadores no Município de Santa Maria, levantando-se a questão sobre o estímulo e suporte, por parte da administração pública municipal, às atividades destes agentes socioambientais.
\end{abstract}

PALAVRAS-CHAVE: desenvolvimento sustentável; resíduos sólidos urbanos; coleta seletiva; associações de catadores e selecionadores de material reciclável.

\section{INTRODUÇÃO}

Consumir para ser feliz. A sociedade pós-moderna possui, indiscutivelmente, uma característica marcante de sua época: o recrudescimento descontrolado do consumo. Invariavelmente, este consumismo tresloucado ${ }^{4}$ vem associado à ideia de felicidade, isto é, vincula-se à satisfação pessoal dos indivíduos, à satisfação de desejos materiais, "como um ato eminentemente social, permeado por fatores de ordem cultural e econômica", conforme esclarece LEMOS (2011, p.22).

\footnotetext{
1 Acadêmica do sexto semestre do Curso de Direito Noturno da Universidade Federal de Santa Maria taticm@yahoo.com.br.

2 Doutora em Direito Ambiental pelo CRIDEAU (Centro de Estudos Interdisciplinares de Direito Ambiental e Urbanismo) da Universidade de Limoges- França. Professora do Departamento de Direito da Universidade Federal de Santa Maria. Email: bia@ufsm.br.

3 Engenheira Ambiental, formada pelo Curso de Engenharia Ambiental no Centro Universitário Franciscano - UNIFRA. Engenheira pela empresa Topographia e Planejamento Rural S/A. Responsável pelo estabelecimento do contato acadêmico com a Associação de Selecionadores de Material Reciclável ASMAR.

${ }^{4}$ Para BAUMAN (2008, p. 41), o consumismo é um atributo da chamada "sociedade de consumidores", sendo responsável por manter a sociedade, como um todo, em movimento e interligada. Através do querer individual, afirma o autor, se estabelece "uma forma de convívio humano".
} 
Esta estreita relação é reflexo de uma cultura imediatista, na qual é necessário ter algo para ser alguém e ter agora. Bombardeados pelos meios de comunicação, os indivíduos são impelidos a consumir constantemente, ultrapassando-se com facilidade a frágil barreira entre o necessário e o dispensável. Como consequência da proliferação do consumo, tem-se uma maior produção de resíduos.

Diante disso, verifica-se o paradoxo existente entre as relações "consumo e felicidade" e "consumo e qualidade de vida", vez que o incremento desregrado da necessidade de ter, como forma de alcançar o contentamento e a plena satisfação, pode, invariavelmente, transformar o meio ambiente em um depósito a céu aberto de resíduos. Disso, por óbvio, decorre um meio ambiente insustentável, sufocado pelo acúmulo resultante de um consumo desnecessário.

Daí se tem o paradoxo entre as referidas relações: há a necessidade de consumir para o alcance da sensação de felicidade suprema, de completude, porém, como consequência de uma sociedade totalmente voltada para o acúmulo de bens materiais se tem uma sociedade soterrada no "lixo", vez que aquilo que se adquiriu ontem, amanhã já se torna velho, defasado, impingindo-se ao indivíduo a vontade de extirpar o ultrapassado para comprar o novo.

Em virtude de tal contexto social e ambiental, a Lei 12.305/10, após longos anos de tramitação junto ao Congresso Nacional, sobreveio ao ordenamento jurídico com o escopo de estimular a sociedade a adotar padrões mais sustentáveis de consumo, bem como, de inovar no que tange às políticas públicas de gestão dos resíduos produzidos.

O presente trabalho constitui-se um resultado ainda incipiente de um estudo em andamento, pertencente ao Projeto de Pesquisa "Olhares Cruzados sobre a Lei da Política Nacional de Resíduos Sólidos: uma abordagem interdisciplinar da lei e das políticas", e será dividido em duas partes. A primeira, contendo algum embasamento teórico e dando destaque aos principais instrumentos adotados pelo mencionado Diploma Legal, intentar-se-á demonstrar a preocupação do legislador com a criação de uma política preventiva e reducionista, no que tange ao consumo e à produção de resíduos (Parte 1.1), destacando-se, ainda, a importância da coleta seletiva e o necessário estímulo a ser destinado ao trabalho desenvolvido pelas associações de catadores de material reciclável (Parte 1.2). 
Já na segunda parte, através de uma análise prática, mais local e realizada através de uma inicial pesquisa de campo, propor-se-á demonstrar de que forma tem se dado a implementação da coleta seletiva no Município de Santa Maria (Parte 2.1), e, em contraposição, buscar-se-á analisar se há, de fato, estímulo às associações de selecionadores de material reciclável existentes, como prevê a legislação em epígrafe, observando-se as dificuldades enfrentadas e o tratamento dispensado as referidas associações. (Parte 2.2).

\section{A nova Lei da Política Nacional dos Resíduos Sólidos como instrumento de alcance do desenvolvimento sustentável}

Em meio a uma sociedade pautada na concepção de que "ter é ser", o consumo desenfreado, facilitado pela globalização e acelerado pela internet, responsável por encurtar (senão acabar com) distâncias, consubstancia-se em uma característica marcante não só das classes sociais mais abastadas, como das classes economicamente menos favorecidas. Busca-se, através da satisfação material, ser feliz. Em virtude disso, transforma-se o espaço social em um depósito de lixo ${ }^{5}$.

Tendo em vista esta conjuntura social e ambiental foram delineadas as diretrizes da Nova Lei da Política Nacional de Resíduos Sólidos - PNRS (Lei 12.305 de 02 de agosto de 2010), cujo texto intentou estimular uma nova cultura respaldada na redução do consumo, trazendo em seu bojo instrumentalidades que visam permitir uma mudança de paradigma capaz de assegurar um meio ambiente sustentável às próximas gerações (parte 1.1). A lei em comento, portanto, não somente estipulou novos rumos no trato dos resíduos sólidos urbanos - RSU, preconizando, a redução da geração de resíduos, a partir da redução do consumo, mas também destacou a importância dos serviços básicos de coleta seletiva e do estímulo às associações de selecionadores de material reciclável,

\footnotetext{
${ }^{5}$ A Lei 12.305/10 traz, em seu artigo $3^{\circ}$, as diferenciações entre os conceitos de rejeito e resíduo sólido. O primeiro consiste naquilo que, após terem sido esgotadas todas as possibilidades de aproveitamento, tratamento e recuperação, não possui mais valor econômico, devendo, portanto, ser correta e ambientalmente destinado. O segundo consubstancia-se, por outro lado, em um bem socioambiental, como pondera LEMOS (2011, p.86), que pode ser reutilizado ou reciclado, possuindo valor econômico e social, na esteira do artigo $6^{\circ}$, inciso VIII, da referida legislação. Ambos, todavia, muitas vezes são utilizados como sinônimo do vocábulo "lixo".
} 
cristalina que há uma necessidade premente de alterar a maneira como se dá, hoje, a relação dos indivíduos com o próprio desejo de consumir ${ }^{7}$.

Neste mesmo sentido, interessante salientar o que também é preconizado no inciso II do referido artigo, o qual destaca uma nova ordem de prioridade a ser delineada, evidenciando que a redução do consumo, precedida pela não geração, é um dos principais desideratos a ser atingido. Alcançar padrões sustentáveis de consumo ${ }^{8}$ parece, ao se analisar a Lei 12.305/10, uma de suas mais relevantes metas, almejandose, assim, concretizar o quase inalcançável desenvolvimento sustentável, refletindo a mudança de paradigma através de algumas das políticas preconizadas no mencionado Diploma Legal.

Para tanto, traz ainda instrumentos capazes de ensejar e possibilitar que se implementem os objetivos ali traçados, a partir das previsões capituladas, por exemplo, nos incisos III e IV do artigo $8^{\circ}$, da Lei 12.305/10. Observa-se que, conforme o citado inciso IV, "o incentivo à criação e ao desenvolvimento de cooperativas ou de outras formas de associação de catadores de materiais reutilizáveis e recicláveis”, é um dos instrumentos criados pelo legislador, a partir de uma genuína preocupação em promover o desenvolvimento econômico também de parcelas menos favorecidas da população, responsáveis por um trabalho de suma importância para a manutenção do equilíbrio ecológico: a coleta seletiva de materiais recicláveis.

\subsection{A importância da coleta seletiva $e$ das associações de catadores $e$} selecionadores de material reciclável

A coleta seletiva foi alçada como um dos instrumentos ${ }^{9}$ de que dispõe a novel legislação, no que tange à gestão e ao gerenciamento dos resíduos sólidos urbanos, tendo, portanto, destaque na construção de medidas para o reiteradamente mencionado desenvolvimento sustentável. Consolida-se, outrossim, em um meio para a concretização da reciclagem, tratando-se, portanto, de instrumento basilar na política de

\footnotetext{
${ }^{7} \mathrm{O}$ artigo $9^{\circ}$, da Lei $12.305 / 10$, traz a seguinte ordem de prioridade na gestão e gerenciamento de resíduos: não geração, redução, reutilização, reciclagem, tratamento de resíduos sólidos e disposição final ambientalmente adequada, demonstrando-se que, primordialmente, busca-se uma política de não geração e redução. Para tanto, primeiramente, necessária uma redução drástica no consumo de bens supérfluos e desnecessários, responsáveis pelo incremento progressivo da geração de resíduos.

${ }^{8}$ Artigo $3^{\circ}$, inciso XIII, da Lei $12.305 / 10$.

${ }^{9}$ Artigo $8^{\circ}$, inciso III, da Lei $12.305 / 10$.
} 


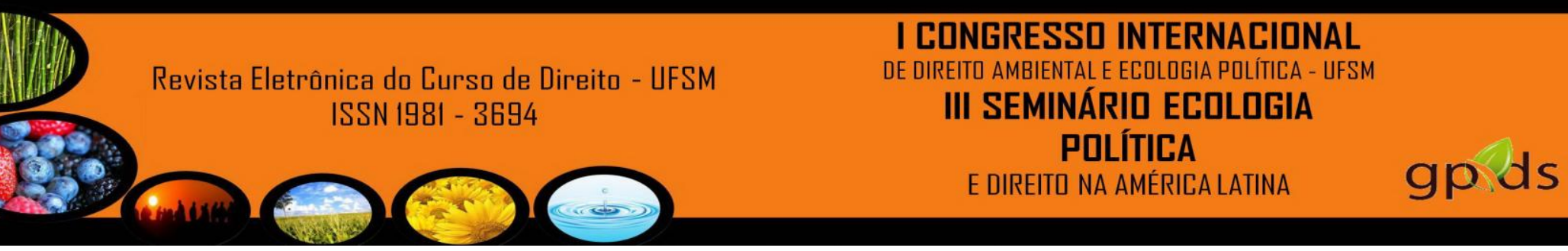

gerenciamento de resíduos, vez que agrega valor àquilo que foi rejeitado e administra o excesso em prol de um meio ambiente equilibrado.

Somados aos benefícios de ordem ambiental, tais como a diminuição da poluição do solo e das águas, a economia de água e energia, a redução da extração vegetal e o estímulo à reciclagem, a coleta seletiva apresenta, ainda, enormes benefícios socioeconômicos, vez que diminui gastos com a limpeza urbana e cria oportunidades de emprego e renda aos catadores de material reciclável, ensejando o fortalecimento de cooperativas de catadores. Ademais, constitui-se em instrumento essencial para se atingir a meta de disposição final ambientalmente adequada dos rejeitos, conforme preceitua o artigo 54, da PNRS $^{10}$.

Nesta senda, em considerando a vital importância da efetivação de tal instrumento, a Lei 12.305/10 buscou garantir aos operadores deste serviço, a valorização e o incentivo a seu trabalho, incumbindo ao poder público o dever de assegurar-lhes as melhores condições laborais possíveis. Não diferente, pois, poderia ser a interpretação dada ao inciso III, do artigo $42^{11}$, ínsito no Capítulo V, da Lei 12.305/10, intitulado "Dos Instrumentos Econômicos". Há, como se percebe, clara intenção do legislador em fomentar a realização de tais serviços, assim como assegurar àqueles que os realizam suporte econômico e logístico, seja através da concessão de isenções fiscais diversas ou por meio da locação ou doação de imóvel e equipamentos necessários para a realização dos serviços.

Impende ressaltar, ademais, que tal estímulo visa a suplementar não somente os serviços de coleta seletiva, tornando-os mais abrangentes e eficazes, mas também incrementar a renda dos trabalhadores, proporcionando-lhes condições mais dignas de trabalho e de sobrevivência.

Portanto, observa-se que a Lei da Política Nacional dos Resíduos Sólidos preocupou-se não somente com o desenvolvimento, por si só, de instrumentos capazes

\footnotetext{
${ }^{10}$ No presente trabalho, não haverão incursões na seara da destinação final dos resíduos, sendo apenas utilizado como exemplo da importância da coleta seletiva para implementação dos objetivos da Lei 12.305/10.

${ }^{11}$ Art. 42. O poder público poderá instituir medidas indutoras e linhas de financiamento para atender, prioritariamente, às iniciativas de:

(..)

III - implantação de infraestrutura física e aquisição de equipamentos para cooperativas ou outras formas de associação de catadores de materiais reutilizáveis e recicláveis formadas por pessoas físicas de baixa renda.
} 
de garantir um tratamento técnico adequado dos resíduos sólidos urbanos, como forma de ir ao encontro das premissas do desenvolvimento sustentável. Como se vê, há também o interesse em instrumentalizar parcelas mais desfavorecidas da população a auxiliarem na realização deste desiderato e, ao mesmo tempo, permitir às mesmas que experimentem um aumento de sua produção e de seus ganhos, associado à possibilidade de uma maior inclusão social. Isso se torna possível, por conseguinte, através do estímulo às associações de selecionadores de material reciclável no desenvolvimento de planos de coleta seletiva.

\section{A coleta seletiva na realidade do Município de Santa Maria: o sistema de} coleta seletiva e a situação da Associação de Selecionadores de Material Reciclável - ASMAR

Tendo em vista que foi abordado no tópico anterior, não restam dúvidas quanto à importância da implementação de um sistema eficiente de coleta seletiva nos municípios. Tal sistema tem o condão de garantir, em menor ou maior medida, que se efetivem princípios e objetivos da Lei 12.305/10, no que tange a um adequado tratamento a ser dispensado na administração dos resíduos sólidos urbanos produzidos por uma população, atuando, ainda, como instrumento de valorização econômica e social dos agentes socioambientais responsáveis pela sua execução.

Nesse norte, os Municípios Brasileiros tem um prazo delimitado no Diploma Legal em comento, a fim de que efetivem, na integralidade, os planos de gestão e gerenciamento de resíduos, sendo a coleta seletiva instrumento imprescindível para tanto. Não diferente, pois, o Município de Santa Maria estabeleceu um programa específico de coleta seletiva, executado por uma associação de selecionadores de material reciclável existente no município há cerca de vinte anos, a ASMAR (parte 2.1). Todavia, em que pese a "novidade"12 para a municipalidade e a importância dos serviços que presta, a associação supramencionada se depara com alguns embaraços no desenvolvimento de seu trabalho relacionados ao precário incentivo que lhes é dado (parte 2.2).

${ }^{12}$ A ASMAR já realizava, independentemente, serviços de coleta seletiva no Município, antes da oficialização dos serviços junto à Prefeitura Municipal. 


\subsection{Coleta Seletiva no Município de Santa Maria}

Buscando-se levar a efeito os preceitos da Lei 12.305/10, a Prefeitura Municipal de Santa Maria implantou o Programa de Coleta Seletiva denominado "Recicla Santa Maria" "13, através dos serviços prestados pela Associação de Selecionadores de Material Reciclável - ASMAR. A associação, que existe desde o ano de 1992, foi contratada, no ano de 2011, através de processo licitatório pela Prefeitura Municipal para realização dos serviços de coleta seletiva no Município e é responsável pelo processo de separação do lixo, realizando o trabalho de prensar e entregar o material a intermediários que o vende às indústrias de reciclagem.

O Programa "Recicla Santa Maria" se dá na forma de uma parceria entre a Prefeitura Municipal e a ASMAR, que é inteiramente responsável pela dinamização e o desenvolvimento dos serviços de coleta seletiva. Através da estruturação de uma rota semanal, a associação coleta resíduos recicláveis, de segunda a sexta-feira, em mais de mil residências de Santa Maria.

Os serviços se implementam através do uso de um caminhão, de propriedade da ASMAR, que foi doado à associação pela Petrobrás através do "Projeto Minuano"14, e consolida-se como resultado de um árduo trabalho de conscientização e educação ambiental no âmbito do Município, realizado durante os cerca de vinte anos de existência da associação. Como se sabe, entretanto, a sociedade em geral apresenta certa relutância em aderir à questão da separação doméstica do lixo. Tome-se como exemplo o próprio Município de Santa Maria: conforme dados do CENSO do ano de 2010, de uma população total de, aproximadamente, 261.031 habitantes (INTITUTO BRASILEIRO DE GEOGRAFIA E ESTATÍSTICA, 2010), apenas cerca de mil residências usufruem atualmente dos serviços de coleta seletiva. Em que pese existirem cadastros diários, buscando a prestação deste serviço junto à ASMAR, é visível a

\footnotetext{
${ }^{13}$ No site da Prefeitura Municipal de Santa Maria, é possível encontrar maiores informações a respeito do Programa de Coleta Seletiva "Recicla Santa Maria". Lá, constam informações a respeito dos tipos de resíduos e instruções sobre a maneira correta de realizar a separação residencial do lixo.

${ }^{14}$ O Projeto Minuano é um programa desenvolvido pela ONG Planeta Vivo e financiado pela Petrobrás Desenvolvimento e Cidadania. Visa à organização e ao auxílio para trabalhadores, além de investimentos com prensa, carrinhos e caminhão para a coleta de resíduos recicláveis. Como se vê, trata-se de um projeto social que busca garantir às associações e cooperativas de catadores de material reciclável melhores condições de trabalho para o desenvolvimento dos serviços de coleta seletiva, bem como, em consequência, promover a melhoria de suas condições socioeconômicas.
} 
específicos a respeito da própria Lei 12.305/10. Afirmou, por fim, que todos os catadores e selecionadores sabem da existência da lei em comento, mas que poucos conhecem, efetivamente, os aspectos legais que dizem respeito à atividade por eles realizada.

Ademais, há outro sério problema, reiteradamente aludido pela representante da associação: a falta de conscientização da sociedade santa-mariense em prol da separação residencial do lixo, que atua como fonte primordial para a realização da coleta seletiva e, consequentemente, a operacionalização da reciclagem de materiais, é incrementada pela deficiente divulgação deste serviço. A coleta seletiva, ainda, não se consolidou em um hábito para os indivíduos e isso entrava, em certa medida, não somente a realização dos serviços, mas também a obtenção de maiores (e melhores) proveitos de tais serviços.

De fato, não se tem nas mídias locais muitas menções ao serviço de coleta seletiva do Município, o que corrobora a ideia de que, somando-se a uma política de educação ambiental, faz-se necessário o apoio do Poder Executivo local na divulgação e incentivo, conforme preceitua a Lei 12.305/10, às associações de catadores de material reciclável e, como corolário lógico, à coleta seletiva.

Assim, não somente a falta de acesso dos próprios "trabalhadores da reciclagem" ao que preconiza a novel legislação minimiza, em parte, as resultantes do significativo trabalho por eles desempenhado, mas igualmente a falta de acesso da população de Santa Maria aos serviços que eles prestam.

Há que se reconhecer, portanto, que ainda carecem as associações santamarienses da devida valorização e do necessário reconhecimento pelo trabalho prestado. Encontra-se, o Município de Santa Maria, pois, encaminhando-se a passos lentos rumo à implementação prática dos objetivos da Lei 12.305/10, vez que, a despeito de ter implementado os serviços de coleta seletiva através da contratação da Associação de Selecionadores de Material Reciclável - ASMAR, impõe-se admitir que a falta de consciência ecológica da população somada ao descaso da Administração no suporte aos catadores ${ }^{17}$ e no estímulo à educação ambiental dos cidadãos, torna mais penosa, neste aspecto, a concretização integral do ideário de desenvolvimento sustentável.

${ }^{17}$ Conforme se verificou, a partir do contato estabelecido com a coordenadora da ASMAR, a falta de esclarecimentos da Prefeitura não é o único problema enfrentado pelos catadores. Há, atualmente, um 


\section{CONCLUSÃO}

Desenvolvimento econômico aliado à manutenção do equilíbrio ecológico constitui-se na premissa básica do desenvolvimento sustentável. Apesar de parecer simples, trata-se de um conceito bastante árduo a ser colocado em prática, principalmente, considerando, como afirma BAUMAN (2008, p.41), a "sociedade de consumidores" em que se vive atualmente.

O acelerado desenvolvimento econômico experimentado pelo país, assim, tem dado azo ao incremento do poder de compra dos cidadãos e, consequentemente, ao aumento considerável do consumo. Vive-se, portanto, em uma sociedade consumista e, como resultante direta desta característica, em uma sociedade produtora, em alta escala, de resíduos.

Destarte, permeada por um clima de prevenção de danos e envolta pela necessidade de operar uma mudança de hábitos na sociedade brasileira, emergiu no ordenamento jurídico a Lei 12.305/10. Este diploma legal, portanto, "nasceu" com o escopo de aparelhar a sociedade na gestão e gerenciamento dos resíduos sólidos urbanos oriundos de uma sociedade pautada no consumo. A necessidade de adequar a aceleração econômica da sociedade à dinâmica da natureza tornou imperiosa a elaboração de um diploma legislativo com "ares de ecologicamente correto".

Através do presente trabalho, buscou-se delinear algumas das diretrizes previstas na Nova Lei da Política Nacional dos Resíduos Sólidos que tratam, justamente, de princípios, objetivos e instrumentos que visam a atingir tal desiderato, enfatizando a relevância dada à coleta seletiva e, consequentemente, àqueles que põem em prática tal serviço: os catadores/selecionadores de material reciclável.

revés bastante polêmico, de natureza estrutural: ocorre que o local onde hoje é realizado o trabalho de separação dos resíduos pelos associados da ASMAR, cedido pelos Irmãos Maristas, foi vendido e está sendo cobrada a retirada de lá dos trabalhadores e dos materiais. Por ora, está em pauta a discussão de um novo local para a sede da associação, não havendo demonstração por parte da Prefeitura de que adquirirá ou cederá a eles um novo espaço para continuarem prestando seus serviços. Fato é, que a ASMAR é contratada da Prefeitura para a realização da coleta seletiva e não pode, portanto, cessá-la. Todavia, ao que parece, negligencia-se, em certa medida, aquilo que preconiza o já referido inciso III, do artigo 42, da Lei 12.305/10. Portanto, além do precário incentivo, desatendimento, também, à legislação. (Entrevista realizada no dia 15 de agosto de 2012, nas dependências da Cooperativa de Estudantes de Santa Maria CESMA, com a colaboração da Engenheira Ambiental, Jaqueline Difante). 



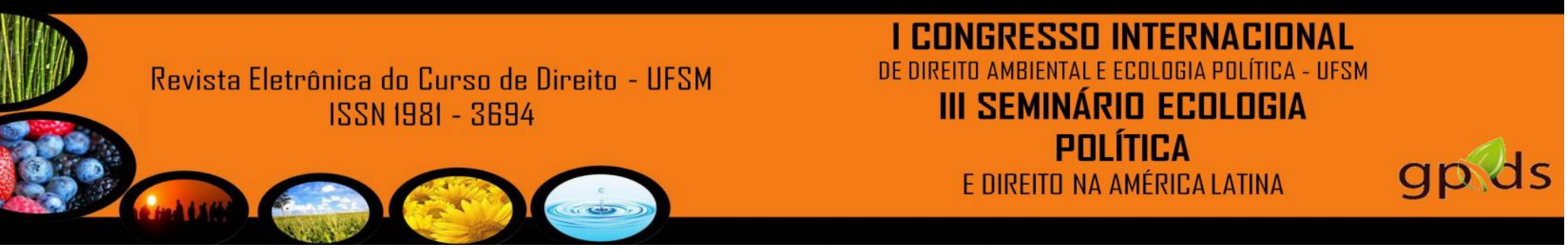

\section{REFERÊNCIAS}

BAUMAN, ZYGMUNT. Vidas para Consumo: a transformação das pessoas em mercadoria. Rio de Janeiro. ZAHAR. 2008.

Brasil. Constituição (1998). Constituição da República Federativa do Brasil: promulgada em 5 de outubro de 1988: atualizada até a Emenda Constitucional n. 68, de 21-12-2011. 7 ed. São Paulo: Saraiva, 2012.

Brasil. Lei n. 6.938, de 31 de agosto de 1981. Institui a de Política Nacional do Meio Ambiente, seus fins e mecanismos de formulação e aplicação, e dá outras providências.. Diário Oficial [da] República Federativa do Brasil. Brasília, DF, $1^{\circ}$ set. 1981. Disponível em: < http://www.planalto.gov.br/ccivil_03/leis/16938.htm>. Acesso em $1^{\circ}$ Setembro 2012.

Brasil. Lei n. 12.305, de 2 de agosto de 2010. Institui a Política Nacional de Resíduos Sólidos; altera a Lei n. 9.605, de 12 de fevereiro de 1998; e dá outras providências. Diário Oficial [da] República Federativa do Brasil. Brasília, DF, 3 ag. 2010. Disponível em: <http://www.planalto.gov.br/ccivil_03/_ato20072010/2010/lei/l12305.htm>. Acesso em 28 Agosto 2012.

FIORILlO, CELSO A. P. Curso de Direito Ambiental Brasileiro. 10 ed. São Paulo. Saraiva, 2009.

INSTITUTO BRASILEIRO DE GEOGRAFIA E ESTATÍSTICA. Censo 2010. Instituto Brasileiro de Geografia e Estatística, 2012. Disponível em: <http://www.ibge.gov.br/cidadesat/topwindow.htm?1>. Acesso em: 31 Agosto 2012.

LEMOS, PATRÍCIA F. I. Resíduos Sólidos e Responsabilidade Civil Pós-Consumo. São Paulo. Revista dos Tribunais, 2011.

PREFEITURA MUNICIPAL DE SANTA MARIA. Recicla. Prefeitura Municipal de Santa Maria, 2012. Disponível em: <http://www.santamaria.rs.gov.br/recicla/>. Acesso em 31 Agosto 2012.

SILVA, JOSE A. Direito Ambiental Constitucional. 6 ed. São Paulo. Malheiros, 2007.

SILVA, Maria Beatriz Oliveira da. Desenvolvimento Sustentável no Brasil de Lula: uma abordagem jurídico-ambiental, Santa Cruz do Sul: EDUNISC; São Paulo: Anita Garibaldi, 2009. 